\title{
Diagnostic Delay of Multiple Sclerosis in a Portuguese Population
}

\section{Atraso no Diagnóstico de Esclerose Múltipla numa População Portuguesa}

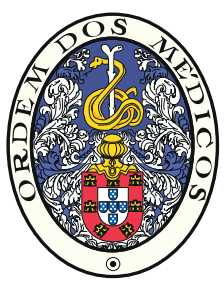

\author{
Ana AIRES $S^{*, 1}$, Ariana BARROS*,2, Célia MACHADO*,3, Diogo FITAS ${ }^{*, 4}$, Gonçalo CAÇÃO*,5, Rui PEDROSA², \\ João CERQUEIRA', \\ Acta Med Port 2019 Apr;32(4):289-294 - https://doi.org/10.20344/amp.11187
}

\section{ABSTRACT}

Introduction: Multiple sclerosis is a chronic inflammatory disease, in which a diagnostic delay could reduce the available therapeutic options. Therefore, it is important to monitor the time to diagnosis and understand factors that may potentially reduce it. The objective of this study was to determine the time between the first symptoms and the diagnosis of multiple sclerosis and which factors may contribute to a diagnostic delay.

Material and Methods: Cross-sectional multicenter study, with retrospective data analysis, conducted in five tertiary Portuguese hospitals. Patients were consecutively selected from each local multiple sclerosis patients' database. Sociodemographic and initial clinical data were collected through a questionnaire. Date of final diagnosis and multiple sclerosis classification was obtained from clinical files.

Results: A total of 285 patients were included with mean age at diagnosis of 36 years. The median time between first clinical manifestation and multiple sclerosis diagnosis was nine months (IQR 2 - 38). Diagnostic delay was associated with an older age ( $p$ $<0.001 ; r=0.35)$, motor deficit at onset [26.5 months (IQR $4.5-56.5) ; p=0.0005]$, higher number of relapses before diagnosis $(p<$ $0.001 ; r=0,626$ ), first observation by other medical specialty [11 months (IQR $2-48$ ); $p<0.001$ ], prior alternative diagnosis [20 months (IQR 4 - 67.5); $p<0.001$ ] and primary progressive subtype [37 months (IQR $25-64.5) ; p<0.001]$. The most significant delay occurred between the initial symptom and neurological observation.

Discussion: A significant delay occurred between initial symptoms and the diagnosis of multiple sclerosis, reflecting the need to increase awareness of this entity and its diverse symptom presentation.

Keywords: Age at Onset; Delayed Diagnosis; Multiple Sclerosis; Referral and Consultation

\section{RESUMO}

Introdução: A esclerose múltipla é uma doença inflamatória crónica na qual um atraso no diagnóstico poderá reduzir as opções terapêuticas, sendo importante monitorizar o tempo até ao diagnóstico e compreender os fatores que potencialmente o reduzam. Foi objetivo deste estudo determinar o tempo entre os primeiros sintomas e o diagnóstico de esclerose múltipla e quais os fatores que podem contribuir para o atraso no diagnóstico.

Material e Métodos: Estudo multicêntrico transversal retrospetivo, realizado em cinco hospitais portugueses. Os doentes foram selecionados, consecutivamente, a partir de bases de dados locais. Os dados sociodemográficos e clínicos iniciais foram adquiridos através de questionário individual. A data do diagnóstico final e a classificação da esclerose múltipla foram obtidas por consulta do processo clínico.

Resultados: Foram incluídos 285 doentes com média de idade ao diagnóstico de 36 anos. A mediana do tempo entre a primeira manifestação clínica e o diagnóstico foi de nove meses (IQR 2 - 38). O atraso no diagnóstico foi associado a idade avançada ( $p<$ $0,001 ; r=0,35)$, défice motor inicial [26,5 meses (IQR 4,5 - 56,5), $p=0,0005]$, maior número de surtos previamente ao diagnóstico ( $p<$ $0,001 ; r=0,626)$, primeira observação por outra especialidade médica [11 meses (IQR 2 - 48); $p<0,001$ ], diagnóstico prévio alternativo [20 meses (IQR 4 - 67,5); $p<0,001$ ] e esclerose múltipla primária progressiva [37 meses (IQR $25-64,5), p<0,001]$. O atraso mais significativo ocorreu entre o primeiro sintoma e a observação por neurologista.

Discussão: Ocorreu um atraso significativo entre o primeiro sintoma e o diagnóstico de esclerose múltipla, refletindo uma necessidade de maior acuidade na identificação dos seus principais sintomas.

Palavras-chave: Diagnóstico Tardio; Encaminhamento e Consulta; Esclerose Múltipla; Idade de Início

\section{INTRODUCTION}

Multiple sclerosis (MS) is a chronic demyelinating and immune-mediated inflammatory disease of the central nervous system (CNS). The diagnosis of MS is based on inter-

national consensus criteria requiring evidence of dissemination of lesions both in time and space. ${ }^{1,2}$

MS has a pre-clinical period during which it is possible

\footnotetext{
* These authors contributed equally to this work.

1. Neurology Department. Centro Hospitalar de São João. Porto. Portugal.

2. Neurology Department. Centro Hospitalar de Lisboa Central. Lisboa. Portugal.

3. Neurology Department. Hospital de Braga. Braga. Portugal.

4. Neurology Department. Unidade Local de Saúde do Alto Minho. Viana do Castelo. Portugal.

5. Neurology Department. Centro Hospitalar do Porto. Porto. Portugal.

6. School of Health Sciences. University of Minho. Braga. Portugal.

7. Unit for Multidisciplinary Research in Biomedicine. Institute of Biomedical Sciences Abel Salazar. University of Porto. Porto. Portugal.

8. Neurology Department. Hospital Beatriz Ângelo. Loures. Portugal.

9. Faculty of Health Sciences. University Fernando Pessoa. Porto. Portugal.

$\square$ Autor correspondente: Carlos Andrade. cjorge.sandrade@gmail.com

Recebido: 19 de agosto de 2018 - Aceite: 26 de novembro de 2018 | Copyright @ Ordem dos Médicos 2019
} 
to detect the presence of demyelinating lesions by magnetic resonance imaging (radiologically isolated syndrome). ${ }^{3}$ In about $90 \%$ of patients, the natural progression of MS follows sequential stages, namely subclinical disease, clinical isolated syndrome, relapsing-remitting and progressive forms. ${ }^{4}$ Inflammation plays an important pathogenic role, especially in the early stages, thus being the main target for currently available treatments. ${ }^{5,6}$ Disease-modifying therapies improve short-term outcomes, but their long-term effects are not yet established. ${ }^{7}$ Nevertheless, there is evidence that these treatments are indeed improving the prognosis of MS. ${ }^{8,9}$ In this context, arguments for an early treatment are reinforced, especially in high-risk patients, ${ }^{10}$ increasing the need for an early diagnosis.

Diagnostic delay could reduce the available therapeutic options and the opportunity for early intervention, ${ }^{3,11}$ which may result in irreversible sequelae. ${ }^{4}$ Moreover, as MS global costs increase with disease severity, ${ }^{12}$ an early diagnosis could also mitigate the economic burden of MS. Consequently, monitoring the time to diagnosis and understanding causes for delays is an important feature when managing MS patients.

The guidelines from the National Institute for Health and Clinical Excellence (NICE) recommend a timeline of 6 weeks from referral to a neurology consultation, and further 6 weeks until any necessary investigation is completed. ${ }^{13,14}$ Nevertheless, diagnostic delay is a common problem across several countries, $3,11,15$ and the reported time from symptom onset to diagnosis vary from 21.5 weeks $^{14}$ to 7 years. $3,11,16,17$

Disease-related or local factors could partly explain this delay. Regarding the former, they are mainly due to difficulties in recognizing the disease, for instance when clinical or radiological features are atypical. ${ }^{18,19}$ Local factors such as different cultures or health care systems (including access to magnetic resonance imaging - MRI) can explain differences across countries. In this sense, it is important to understand which factors are associated with diagnostic delay and how these influences the disease prognosis. ${ }^{16}$

The aims of this study are to determine the time between the first clinical manifestation and MS diagnosis and which factors may contribute to a diagnostic delay in a cohort of Portuguese MS patients.

\section{MATERIAL AND METHODS}

A cross-sectional multicentre study, with retrospective data collection, was conducted in five tertiary hospitals, located in different regions of Portugal. Written informed consent was obtained from all patients. The ethics committee of each centre approved the study protocol.

Eligible patients were adult (aged $\geq 18$ years) with clinical isolated syndrome (CIS) or MS (according to revised McDonald criteria) ${ }^{1}$ diagnosed between January 2010 and December 2015. Patients were consecutively selected from each local MS patients' database and all eligible patients were invited to participate in the study by letter and phone call. Sociodemographic and initial clinical data were collect- ed through a questionnaire, including: age, gender, education, age and date (month and year) of disease onset, initial symptom, first diagnosis (neurological versus other), initial medical assessment (neurology consultation versus other medical specialty), number of relapses before diagnosis and date of the first neurological evaluation. Further data were collected from patients' medical records, including date of final diagnosis and MS classification: CIS or relapsing-remitting (RRMS), secondary progressive (SPMS) and primary progressive (PPMS).

Patients were asked to characterise and to date the initial symptom, which was only considered if consistent with a relapse (occurrence of a new neurological deficit or worsening of a prior one, lasting at least 24 hours and separated from the previous event for at least one month). When there was a discrepancy with medical records, the patients' answers were assumed for the analysis.

The primary endpoint was to determine time between the first clinical manifestation and CIS/MS diagnosis (diagnostic delay). The secondary endpoint was to determine the possible influence of sociodemographic and clinical factors on the time to diagnosis.

\section{Statistical analyses}

All analyses were performed using SPSS (Statistical Package for the Social Sciences) version 20 (Chicago, IL). Descriptive statistics were used to describe continuous variables. Categorical variables were presented as numbers and percentages.

Chi Square test or Fisher's exact test was used for comparison between categorical variables. The association between two quantitative variables was performed through Pearson correlation coefficient or Spearman correlation coefficient (depending on the data distribution). Multivariable logistic regression analysis was used to determine factors that could be considered as independent predictors of diagnosis delay. Only variables presenting a correlation to the outcome $(p<0.05)$ were included as potential predictors, with the exception of the first specialty observation. $P$ value $<0.05$ was considered as statistically significant for all tests.

\section{RESULTS}

In this study, 285 patients with MS were included, the vast majority with RRMS/CIS forms $(n=251 ; 88 \%)$. The sociodemographic, clinical characteristics and data concerning the process of diagnosis are presented in Table 1. Most patients were female (67.4\%; female/male ratio: 2.06 ), the median age was 40 years (range: 21 to 75 years), and the median age at diagnosis was 36 years (IQR 26.5-45.0).

The median time between first clinical manifestation and MS diagnosis was 9 months (IQR 2-38), without significant differences between sex $(p=0.809)$. The median time between first symptom and neurological observation was 5 months (IQR 0-28), afterwards the median time until diagnosis was 0 months (IQR 0-2). We found a positive correlation between the age at diagnosis and the diagnostic delay $(p<0.001 ; r=0.350)$. 
Table 1 - Sociodemographic and clinical characteristics

\begin{tabular}{|c|c|c|c|}
\hline & $\begin{array}{c}\text { Total } \\
(\mathrm{n}=\mathbf{2 8 5})\end{array}$ & $\begin{array}{l}\text { Median diagnosis delay in months } \\
\text { (IQR) }\end{array}$ & $p$-value \\
\hline \multicolumn{4}{|l|}{ Sex, n (\%) } \\
\hline Men & $93(32.6 \%)$ & $8(1-41)$ & $0.809^{a}$ \\
\hline Women & $192(67.4 \%)$ & $9(2-36)$ & \\
\hline \multicolumn{4}{|l|}{ Age, n (\%) } \\
\hline Current age & $40(30.5-49.0)$ & & \\
\hline Age at diagnosis & $36(26.5-45.0)$ & & \\
\hline \multicolumn{4}{|l|}{ Time variables (months) } \\
\hline Since first symptom to diagnosis & & $9(2-38)$ & \\
\hline Since first symptom to neurological observation & & $5(0-28)$ & \\
\hline Since neurological observation to diagnosis & & $0(0-2)$ & \\
\hline \multicolumn{4}{|l|}{ Academic degree, $\mathrm{n}(\%)$} \\
\hline $1-4$ years & $19(6.7 \%)$ & $28(1-57)$ & $0.157^{a}$ \\
\hline $5-6$ years & $19(6.7 \%)$ & $8(3-61)$ & \\
\hline 7 - 9 years & $51(17.9 \%)$ & $12(3-30)$ & \\
\hline $10-12$ years & $74(26.0 \%)$ & $13(3-41)$ & \\
\hline Higher education & $122(42.8 \%)$ & $4(1-35)$ & \\
\hline \multicolumn{4}{|l|}{ Initial assessment, by medical specialty, $\mathrm{n}(\%)^{\mathrm{b}}$} \\
\hline Neurology & $83(32.2 \%)$ & $3(0-13)$ & \\
\hline General Practitioner & $78(30.2 \%)$ & $18(4-58)$ & \\
\hline Ophthalmology & $33(12.8 \%)$ & $4(1-28)$ & $<0.001^{\circ}$ \\
\hline Orthopaedics & $17(6.6 \%)$ & $8(4-36)$ & \\
\hline Neurosurgery & $16(6.2 \%)$ & $32(4-63)$ & \\
\hline Internal Medicine & $14(5.4 \%)$ & $4(1-15)$ & \\
\hline Otorhinolaryngology & $9(3.5 \%)$ & $11(1-83)$ & \\
\hline Others & $8(3.1 \%)$ & - & \\
\hline MS Classification & & & $<0.001^{\mathrm{a}}$ \\
\hline RRMS/CIS & $251(88 \%)$ & $7(1-33)$ & \\
\hline SPMS & $8(3 \%)$ & ) & \\
\hline PPMS & $26(9 \%)$ & $37(25-64.5)$ & \\
\hline
\end{tabular}

${ }^{a}$ Mann-Whitney non-parametric test.

${ }^{\mathrm{b}}$ Percentages were calculated considering 258 patients (patients with information regarding initial medical assessment).

${ }^{c}$ Non-parametric test (Mann-Whitney) comparing initial medical assessment by Neurology vs other medical specialties ( 3 vs 11 months, $\left.p<0.001\right)$.

Diagnostic delay was defined as the time between patient's first symptom and MS diagnosis.

Patients who were first examined by a neurologist presented a statistically significant shorter time to diagnosis compared to those observed by another medical specialty (3 months (IQR 0-13.3) vs 11 months (IQR 2-48); p < 0.001). Twenty-seven patients (9.5\%) did not seek medical assistance after appearance of the first clinical symptoms. No statistically significant differences were observed between academic qualifications and time to diagnosis $(p=0.157)$.

Regarding the initial clinical symptoms (Table 2), sensory changes were the most frequent $(39.0 \%)$, followed by cranial nerve disturbance $(26.0 \%)$, motor deficit symptoms $(21.0 \%)$, ataxia $(13.3 \%)$ and psychiatric symptoms $(0.7 \%)$. Cranial nerve disturbance was the presentation leading to an earlier diagnosis. Patients presenting with motor deficit $(n=60)$ had the longest diagnostic delay $(p<0.001)$; in this group, 17 patients were first observed by a neurologist and
8 did not seek medical assistance after appearance of the first clinical symptoms.

A total of $128(44.9 \%)$ patients had a prior alternative diagnosis and a statistically significant longer time to MS diagnosis: 20 (IQR 4-67.5) months vs 5 (IQR 1-22) months for those without a prior alternative diagnosis $(p<0.001)$. The correlation between the number of relapses and the time to diagnosis was positive and statistically significant ( $p$ $<0.001 ; r=0.626$ ).

Regarding MS classification, patients with RRMS/CIS/ SPMS had a statistically significant shorter time to diagnosis when compared to those with PPMS: 7 (IQR 1-33) months vs 37 (IQR 25-64.5) months, respectively $(p<0.001)$.

Finally, multivariable logistic regression demonstrated that motor symptoms at onset (odds ratio [OR]: 0.344 ), prior incorrect diagnosis (OR: 0.378) and age (OR: 0.948) were 
Table 2 - Initial symptoms and first diagnosis

\begin{tabular}{|c|c|c|c|}
\hline & $\begin{array}{c}\text { Total } \\
(n=285)\end{array}$ & $\begin{array}{l}\text { Diagnosis delay in months } \\
\text { (IQR) }\end{array}$ & $p$-value \\
\hline \multicolumn{4}{|l|}{ Onset symptom, n (\%) } \\
\hline Sensory disturbance & $111(38.9 \%)$ & $7(2-26)$ & \multirow{5}{*}{$<0.001^{\mathrm{a}}$} \\
\hline Cranial nerve disturbance (including optic neuritis) & $74(26.0 \%)$ & $3.5(0-27.5)$ & \\
\hline Motor deficit & $60(21.1 \%)$ & $26.5(4.5-56.5)$ & \\
\hline Ataxia & $38(13.3 \%)$ & $11(2.75-33)$ & \\
\hline Psychiatric & $2(0.70 \%)$ & - & \\
\hline \multicolumn{4}{|l|}{ Number of relapses before the first, $n(\%)$} \\
\hline None & $111(38.9 \%)$ & & \\
\hline One & $111(38.9 \%)$ & & \\
\hline Two & $34(12.0 \%)$ & & \\
\hline More than two & $29(10.2 \%)$ & & \\
\hline \multicolumn{4}{|l|}{ Other diagnoses prior to MS diagnosis, $\mathrm{n}(\%)$} \\
\hline No & $157(51.1 \%)$ & $20(4-67.5)$ & \\
\hline Yes & $128(44.9 \%)$ & $5(1-22)$ & \\
\hline Orthopaedics & $36(28.1 \%)$ & & \\
\hline Psychiatric & $30(23.4 \%)$ & & \\
\hline Neurosurgical & $14(10.9 \%)$ & & \\
\hline Ophthalmologic & $13(10.1 \%)$ & & $<0.001^{\text {b }}$ \\
\hline Otorhinolaryngologic & $10(7.8 \%)$ & & \\
\hline Other Neurologic & $5(3.9 \%)$ & & \\
\hline Vascular & $2(2.3 \%)$ & & \\
\hline Others & 17 (13.3\%) & & \\
\hline
\end{tabular}

aruskal-Wallis non-parametric test

${ }^{\mathrm{b}}$ Mann-Whitney non-parametric test

${ }^{c}$ Percentages were calculated considering 128 patients (patients with prior alternative diagnosis information).

independently associated with MS diagnostic delay (Table

3). Simple linear regression showed that for each year of age at diagnosis, an increase of 1.326 months in time to diagnosis is expected.

\section{DISCUSSION}

In our study, the median time between the first clinical manifestation and MS diagnosis was 9 months. The most significant delay occurred between the first symptom and neurological observation; after this, the median time to diagnosis was 0 months. In addition, we identified several factors that could contribute to this delay in our patients.

Patients' age at diagnosis significantly influenced the diagnosis delay, with older patients presenting a longer time to diagnosis. We hypothesize that this was mainly due to an age-related broader differential diagnosis of MS: osteoarthritis may impair motor function and gait, brainstem symptoms such as vertigo may be attributed to vertebrobasilar ischemic attacks, ${ }^{20}$ bladder dysfunction can be seen as a consequence of prostatic hypertrophy or weakness of pelvic floor muscles in women, and optic neuritis may be interpreted as ischemic optic neuropathy. ${ }^{21}$ Moreover, with age, brain MRI may disclose some vascular white matter changes, further contributing to some difficulties regarding diagnosis. ${ }^{22}$
Like in other studies, ${ }^{3}$ the most significant delay was between the time of first symptom and the first neurological evaluation. Almost one third of patients were first examined by a neurologist, a factor that was associated with a significant decrease in the diagnostic delay when compared to an initial observation by another medical or surgical specialist $(p<0.05)$.

Although we cannot completely determine where the delay occurred, this may be due to an under recognition of MS by other medical specialties, the time taken by the patient to seek medical attention and/or a difficult access to specialty appointments.

It is known that diagnostic errors are common and underemphasized, but they are also challenging to detect and dissect. ${ }^{23}$ Like some other diseases, MS is often difficult to diagnose early in its course and there are several diseases and syndromes that may mimic this condition. Furthermore, several studies suggest that an important reason for MS diagnostic delay is the non-recognition of some of the symptoms, often resulting in misdiagnosis. ${ }^{24,25}$ Our study shows that almost half of the patients received an incorrect prior diagnosis and this led to a longer delay on MS diagnosis. This is probably explained by the "multi-symptom" nature of this disease, which renders the diagnosis difficult, especially for those who are not closely acquainted with it. 
Table 3 - Logistic regression for lower time until diagnosis ( $\leq 9$ months)

\begin{tabular}{|c|c|c|c|c|c|c|}
\hline & \multicolumn{3}{|c|}{ Initial model } & \multicolumn{3}{|c|}{ Optimized model } \\
\hline & OR & $95 \% \mathrm{Cl}$ for OR & $p$-value & OR & $95 \% \mathrm{Cl}$ for OR & $p$-value \\
\hline Age at diagnosis (years) & 0.953 & $0.930-0.977$ & $<0.001$ & 0.948 & $0.926-0.972$ & $<0.001$ \\
\hline \multicolumn{7}{|l|}{ Symptoms } \\
\hline 1 - Cranial nerves disturbance & Ref. & & & & & \\
\hline 2 - Motor & 0.422 & $0.185-0.961$ & 0.040 & 0.344 & $0.158-0.747$ & 0.007 \\
\hline 3 - Sensitive & 0.625 & $0.327-1.197$ & 0.156 & 0.616 & $0.321-1.183$ & 0.146 \\
\hline 4 - Ataxia & 0.461 & $0.196-1.081$ & 0.075 & 0.441 & $0.188-1.036$ & 0.060 \\
\hline 6 - Psychiatric & 0.887 & $0.052-15.260$ & 0.934 & 0.933 & $0.054-16.043$ & 0.962 \\
\hline \multicolumn{7}{|l|}{ Diagnosis } \\
\hline Incorrect diagnosis & 0.394 & $0.235-0.662$ & $<0.001$ & 0.378 & $0.226-0.632$ & $<0.001$ \\
\hline Correct diagnosis & Ref. & & & & & \\
\hline \multicolumn{7}{|l|}{ MS type } \\
\hline PPMS & 0.379 & $0.096-1.497$ & 0.167 & - & - & - \\
\hline CIS/RRMS/SPMS & Ref. & & & Ref. & & \\
\hline$p$-value & & - & & & $<0.001$ & \\
\hline Hosmer and Lemeshow test & & - & & & 0.212 & \\
\hline Overall percentage & & - & & & $67.0 \%$ & \\
\hline
\end{tabular}

OR: odds ratio; $95 \%$ Cl for OR: $95 \%$ confidence interval for the odds ratio; Ref: category versus the one is making comparisons

From a clinical point of view, sensory symptoms, cranial nerve disturbance (including optic neuritis), motor deficit and ataxia were the most common onset symptoms. The difference between the diagnostic delay according to the onset symptom was statistically significant, which reflects that some onset symptoms immediately prompt the diagnosis, as observed by those with a cranial nerve disturbance presentation. Interestingly, motor deficits have a considerable long diagnostic delay, fitting previous reports. ${ }^{11,26}$ In our study, only a minority of patients with a motor deficit presentation $(28 \%)$ were first observed by a neurologist, which could explain part of this delay.

Lastly, we verified a longer time to diagnosis in patients with PPMS when compared with RRMS, which is consistent with previous reports. ${ }^{11}$ PPMS is characterized by a gradual change in terms of disability, typically lacking relapses, making it harder to be recognized. Moreover, patients are usually older at onset and a progressive paraparesis is a common presentation, which widens the differential diagnosis. ${ }^{22,27}$

This study has some limitations. First, data collection was mainly based on patients' answers. Although asking for past neurological events is crucial while performing a suspected MS clinical history with implication in the diagnostic criteria, ${ }^{1}$ the recollection of the exact date may be subjected to a memory bias. This poses a particular problem in patients with "benign" MS, in whom relapses can happen with several years apart and only a mild disability is seen, or in PPMS due to its absence of attacks. We tried to mitigate this by comparing patients' answers to medical records and inquired back if any discrepancies were detected.

Another drawback is that we did not systematically evaluate the presence of other coexisting diseases, which may also contribute to a delay in the diagnosis of MS. ${ }^{16}$ Previous studies have shown that comorbidity and lifestyle factors are associated with longer time between symptom onset and diagnosis. ${ }^{16}$ First, pre-existing disease, or adverse effects of medications used to treat it, can conceal new symptoms, or the patient can attribute new symptoms to the known disease which has already been diagnosed. Second, the physician must also acknowledge that the new symptom is not attributable to a pre-existing disease and that it demands further diagnostic testing. Finally, the diagnostic test results must be interpreted correctly, again with the potential risk of failure in cases where pre-existing disease complicate this interpretation. ${ }^{16,17}$

We considered sample size a strength of this study, since MS prevalence in Portugal is $46.3 / 100,000$ inhabitants, ${ }^{28}$ affecting about 5000 people. Moreover, we included centres located in some of the main demographic regions of Portugal and we thoroughly reviewed the major clinical and sociodemographic factors presented by our patients that could impact the aim of the study.

In conclusion, the complexity of MS poses several diagnostic difficulties. Neurologists who specialize in MS together with their multidisciplinary teams, are ideally placed to establish the diagnosis of MS and guide its management. However, significant delays still occur between noticing the first symptoms and the final diagnosis of MS, in part due to a misinterpretation of patients' complains. Although the future development of reliable MS biomarkers would facilitate the diagnosis and thereby reduce its delay, it is necessary to increase awareness of this entity and its diverse symptom presentation, especially among patients and other medical specialties apart from Neurology. 


\section{ACKNOWLEDGEMENTS}

The authors are grateful to Eurotrials, Scientific Consultants for the review of the statistical analysis and medical writing assistance.

\section{PROTECTION OF HUMANS AND ANIMALS}

The authors declare that the procedures were followed according to the regulations established by the Clinical Research and Ethics Committee and to the Helsinki Declaration of the World Medical Association.

\section{DATA CONFIDENTIALITY}

The authors declare having followed the protocols in use at their working center regarding patients' data publication. Patient consent obtained.

\section{CONFLICTS OF INTEREST}

The authors declare they have no conflicts of interest for this manuscript.

\section{FUNDING SOURCES}

This research had a financial support of Biogen Idec, Inc.

clinical practice. Mult Scler. 2011;17:1017-21.

1. Polman $\mathrm{CH}$, Reingold SC, Banwell B, Clanet M, Cohen JA, Filippi M, et al. Diagnostic criteria for multiple sclerosis: 2010 revisions to the McDonald criteria. Ann Neurol. 2011;69:292-302.

2. Thompson AJ, Banwell BL, Barkhof F, Carroll WM, Coetzee T, Comi G, et al. Diagnosis of multiple sclerosis: 2017 revisions of the McDonald criteria. Lancet Neurol. 2018;17:162-73.

3. Fernandez O, Fernandez V, Arbizu T, Izquierdo G, Bosca I, Arroyo R, et al. Characteristics of multiple sclerosis at onset and delay of diagnosis and treatment in Spain (the Novo Study). J Neurol. 2010;257:1500-7.

4. Miller JR. The importance of early diagnosis of multiple sclerosis. J Manag Care Pharm. 2004;10:S4-11.

5. Mendes A, Sa MJ, Classical immunomodulatory therapy in multiple sclerosis: how it acts, how it works. Arq Neuropsiquiatr. 2011;69:536-43.

6. Thompson AJ, Baranzini SE, Geurts J, Hemmer B, Ciccarelli O. Multiple sclerosis. Lancet. 2018;391:1622-36.

7. Derfuss T, Kappos L. Evaluating the potential benefit of interferon treatment in multiple sclerosis. JAMA. 2012;308:290-1.

8. University of California - San Francisco MS-EPIC Team, Cree BA Gourraud PA, Oksenberg JR, Bevan C, Crabtree-Hartman E, et al. Long-term evolution of multiple sclerosis disability in the treatment era. Ann Neurol. 2016;80:499-510.

9. Trojano M, Pellegrini F, Fuiani A, Paolicelli D, Zipoli V, Zimatore GB, et al. New natural history of interferon-beta-treated relapsing multiple sclerosis. Ann Neurol. 2007;61:300-6.

10. Kappos L, Edan G, Freedman MS, Montalban X, Hartung HP, Hemmer $B$, et al. The 11-year long-term follow-up study from the randomized BENEFIT CIS trial. Neurology. 2016;87:978-87.

11. Kingwell E, Leung AL, Roger E, Duquette P, Rieckmann P, Tremlett $\mathrm{H}$, et al., Factors associated with delay to medical recognition in two Canadian multiple sclerosis cohorts. J Neurol Sci. 2010;292:57-62.

12. Sá MJ, Kobelt G, Berg J, Capsa D, Dalén J; European Multiple Sclerosis Platform. New insights into the burden and costs of multiple sclerosis in Europe: Results for Portugal. Mult Scler. 2017;23:S143-54.

13. Multiple sclerosis in adults: management. Clinical guideline [CG186]. October 2014.. [accessed 2017 Apr 11]. Available from: https://www. nice.org.uk/guidance/cg186.

14. Adamec I, Barun B, Gabelic T, Zadro I,Habek M. Delay in the diagnosis of multiple sclerosis in Croatia. Clin Neurol Neurosurg. 2013;115:S70-2.

15. Kelly SB, Chaila E, Kinsella K, Duggan M, McGuigan C, Tubridy N, et al., Multiple sclerosis, from referral to confirmed diagnosis: an audit of
16. Marrie RA, Horwitz R, Cutter G, Tyry T, Campagnolo D, Vollmer T. Comorbidity delays diagnosis and increases disability at diagnosis in MS. Neurology. 2009;72:117-24.

17. Thormann A, Sorensen PS, Koch-Henriksen N, Laursen B, Magyari M Comorbidity in multiple sclerosis is associated with diagnostic delays and increased mortality. Neurology. 2017;89:1668-75.

18. Rocha AJ, Littig IA, Nunes RH, Tilbery CP. Central nervous system infectious diseases mimicking multiple sclerosis: recognizing distinguishable features using MRI. Arq Neuropsiquiatr. 2013;71:73846.

19. Miller DH, Weinshenker BG, Filippi M, Banwell BL, Cohen JA, Freedman MS, et al. Differential diagnosis of suspected multiple sclerosis: a consensus approach. Mult Scler. 2008;14:1157-74.

20. Polliack ML, Barak $\mathrm{Y}$, Achiron A. Late-onset multiple sclerosis. J Am Geriatr Soc. 2001;49:168-71.

21. Martinelli V, Rodegher M, Moiola L, Comi G. Late onset multiple sclerosis: clinical characteristics, prognostic factors and differential diagnosis. Neurol Sci. 2004;25:S350-5.

22. Palace J. Making the diagnosis of multiple sclerosis. J Neurol Neurosurg Psychiatry. 2001;71:ii3-8.

23. Schiff GD, Kim S, Abrams R, Cosby K, Lambert B, Elstein AS. Agency for Healthcare Research and Quality. Diagnosing diagnosis errors: lessons from a multi-institutional collaborative project. In: Henriksen K, Battles JB, Marks ES, Lewin DI, eds. Advances in Patient Safety: From Research to Implementation: Volume 2: Concepts and Methodology. Rockville: Agency for Healthcare Research and Quality; 2005:255-78.

24. Farber R, Hannigan C, Alcauskas M, Krieger S. Emergency department visits before the diagnosis of MS. Mult Scler Relat Disord. 2014;3:350-4.

25. Levin N, Mor M, Ben-Hur T. Patterns of misdiagnosis of multiple sclerosis. Isr Med Assoc J. 2003;5:489-90.

26. Kingwell E, Leung AL, Roger E, Duquette P, Rieckmann P, Tremlett H. Factors associated with delay to medical recognition in two Canadian multiple sclerosis cohorts. J Neurol Sci. 2010;292:57-62.

27. Willis MA, Fox RJ. Progressive multiple sclerosis. Continuum. 2016;22:785-98.

28. De Sa J, Paulos A, Mendes H, Becho J, Marques J, Roxo J. The prevalence of multiple sclerosis in the district of Santarem, Portugal. J Neurol. 2006;253:914-8. 